\title{
A CONCEPTUAL FRAMEWORK FOR SERIOUS GAMES
}

\author{
Amri Yusoff, Richard Crowder, Lester Gilbert, and Gary Wills \\ University of Southampton, Southampton, UK \\ $\{a y 06 r, r m c, l g 3, . g b w\} @ e c s . s o t o n . a c . u k$
}

\begin{abstract}
A considerable number of serious games have been developed over the last ten years, with varying degrees of success. Due to a lack of clear standards and guidelines for game developers, it is difficult to justify claims that a specific game meets the learner's requirements and/or expectations. This paper defines a conceptual model for serious games that will contribute to their design and the measurement of achievement in meeting their learning outcomes.
\end{abstract}

\section{Introduction}

There are a number of definitions for serious games and Susi et al [1] define them as games that engage the user and contribute to the achievement of predefined objectives. For example, the U.S. Army uses serious games for tactical and strategic training which allows trainees to participate in simulated real world battles [2].

The growth of serious games in education can be ascribed to learning which can be more engaging with the introduction of an underlying game, and to the current generation of learners who have grown up in a digital environment and are familiar with its operation. It is apparent that the delivery and organization of teaching material needs to be changed to accommodate young learners and to meet their expectations [3]. Providing these learners with suitable games could be one of the solutions for meeting these needs, together with the support of traditional teaching in the classroom.

However, due to unclear standards and guidelines, it is difficult to claim that serious games really meet the learner's requirements or expectations. One view is that most of the available games for learning have not been created by language or pedagogy experts [4].

In order to address the problems caused by unclear standards, this paper defines a conceptual model for serious games based on learning theory. This will assist developers in ensuring that the resultant serious game will provide effective learning.

\section{Serious Games Conceptual Framework}

The proposed framework includes learning and pedagogy theory in combination with gaming requirements [5-8] and aims to establish a conceptual model that will be used by the game designer or educational practitioner when designing serious games for effective learning.

The framework in Figure 1 is an evolution of the input-process-outcome game model discussed by Garris et al [5].

\subsection{Capability}

Capability refers to the cognitive, psychomotor, and possibly affective skills which the learner is to develop as a result of playing the game. Cognitive skills include the capabilities of recall, analysis, synthesis, and evaluation. Psychomotor skills include the capabilities of well-timed, fluid execution. Affective skills include the capabilities of identifying, adopting, and valuing appropriate attitudes and points of view.

\subsection{Instructional content}

The instructional content is the subject matter that it is intended that the learner should learn. The detail of the actual subject matter to learn, or the type of content that the learner learns, could be an exhaustive list. Gilbert \& Gale [7] state that contents can be classified into four types: facts, procedures, concepts, and principles.

\subsection{Intended learning outcomes}

Learning outcomes are the goals to be achieved from playing the serious game. An intended learning. 


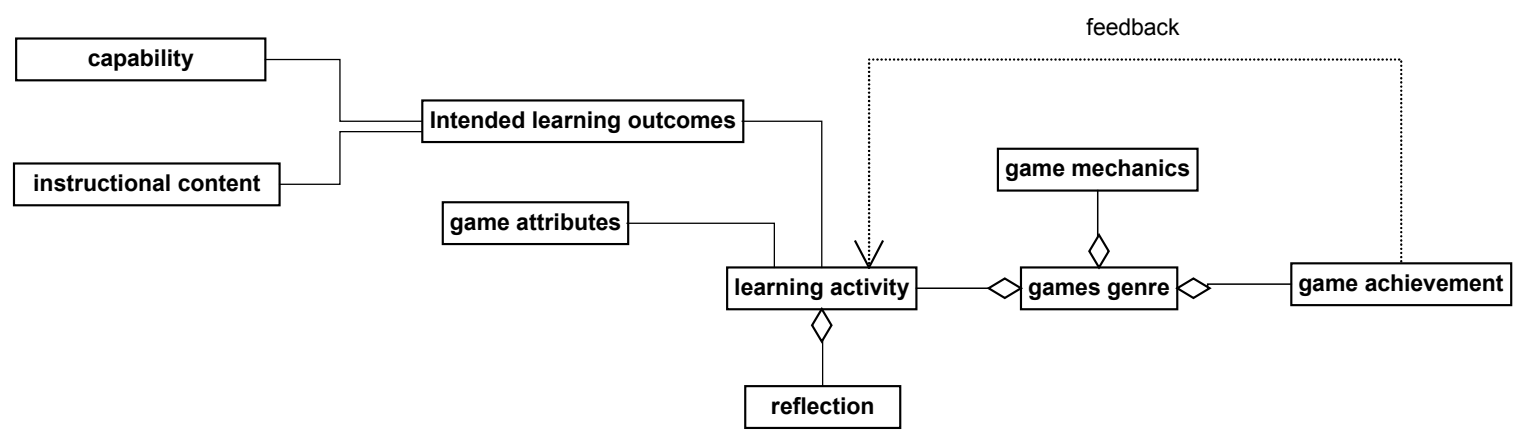

Figure 1. Conceptual Framework for Serious Games shown as a Structural Class diagram.

outcome is a particular combination of capability and subject matter. For example, the learner should be able to recall the date of the battle of Hastings or should be able to analyse whether a particular bird is a raptor

Typical examples of learning outcomes are based on taxonomies of educational objectives with learner capabilities drawn from the psychomotor, cognitive, and affective domains [7] For example, pilots undertake rigorous training in both the classroom and in aircraft. A study has shown that by introducing a number of hours playing aviation computer games, pilots have performed better in test flights.

\subsection{Game attributes}

Game attributes are those aspects of a game which support learning and engagement. The game attributes are developed based on the critical thinking resulting from the literature review on behaviourist, cognitive, constructivist, educationist, and neuroscience perspectives. The game attributes include:

- Incremental learning provides the learning materials and introduces the learning activities incrementally. Intended learning outcomes are addressed one by one and not all at once.

- Linearity is the extent to which the learning activities are sequenced by the game (and would suit a serial learning style), and the extent to which an active learner may be able to construct their own sequences.

- Attention span concerns the cognitive processing and short-term memory loads placed upon the learner by the game. These loads need to be carefully calibrated to the target learner.

- Scaffolding is the support and help given by the game during the learning activities.
- Transfer of learned skills is the support provided by the game to enhance the application of previously learned knowledge to other game levels.

- Interaction is the extent to which the game activities require responses and engagement from the learner.

- Learner control is the extent to which the learner can direct their learning activities within the game, providing self study and self exploration to suit their own pace and experience.

- Practice and drill provides for repeating learning activities with increasingly harder tasks for better achievement of the intended learning outcomes.

- Intermittent feedback is the extent to which every game interaction receives feedback, or whether feedback is provided less frequently.

- Rewards are arrangements in the game to encourage the learner and to keep their motivation high.

- Situated and authentic learning involves the provision of a gaming environment or world where the learner can relate their learning to their needs and interests in the outside world.

- Accommodating to the learner's styles refers to the game's ability to suit and to reach out to different learner styles by offering variation in game play.

\subsection{Learning activity}

Learning activity is the activity designed to keep the learner engaged and learning in the game world. The deep involvement or immersion by the learner depends on the effectiveness on the delivery of these activities.

Gilbert \& Gale [7] suggested a number of methods for constructing learning activities to support given intended learning outcomes. For example, if a learner 
needs to be able to recall a concept, the learning activities would include showing an example of the concept and asking the learner for the concept name, followed by feedback on the answer.

The activity should involve learning materials that are appropriate and challenging for the target learner seeking competency at a level slightly above that of the learner's current competency [9]. The majority of the game designers spend considerable time in perfecting this area of "game play" in order to make the game successful.

\subsection{Reflection}

Reflection is where the learner thinks about the purpose of the learning activities that have been undertaken, and decides the strategy to apply during the next activity. Reflection should take place within the game without letting the learner step out of the game world, and this can be done by offering reflection activities within the game. Garris et al [5] have stated that the reflection activity can be included within the game by providing a description, an explanation of why this activity is chosen, a discussion of the errors made by the learner, and some corrective suggestions.

\subsection{Games genre}

Game genre is the type or category of the game played. Genres range from "beat-em-ups", through open-world sandboxes, to strategy games, and simulation. More recently game designers have developed serious games adopted for learning purposes according to games genres..

\subsection{Game mechanics}

Game mechanics and game rules define the details of the game [6]. If the game genre is a Real Time Strategy (RTS), for example, then it may require game mechanics of resource management and territory control. The desired learning activities and required instructional content influence the selected game mechanics in order to design a better game that will suit a particular style of learning, a particular target learner, or a particular set of intended outcomes.

\subsection{Game achievement}

Game achievement is the level of learner achievement in playing these games. This achievement can be indicated by the game scores, total amount of resources or assets collected within the game, or time taken to achieve game goals. In addition, it gives the pleasure of reward to the learner, and also serves a purpose of learner assessment.

The learning activities can be modified based on the game achievement's feedback. The game achievement or score would indicate the level of learner knowledge while playing games and, if necessary, newly chosen learning activities should be changed to suit the learner level.

\section{Conclusion}

The serious games framework shows the major components that create an effective model for learning through the use of serious games. Every component inside this framework plays a role to ensure that learning would take place while playing the game. We propose this framework as an appropriate basis for effective serious games design for designers and teaching practitioners.

\section{References}

[1] T. Susi, M. Johannesson, and P. Backlund, "Serious Games - An Overview," School of Humanities and Informatics, University of Skövde, Sweden, Technical Report HS-IKI-TR-07-001, 2007.

[2] N. Iuppa and T. Borst, Story and simulations for serious games : tales from the trenches. Oxford: Burlington, 2007.

[3] T. C. Reeves, "Do Generational Differences Matter in Instructional Design?," Instructional Technology Forum, January 2008.

[4] D. R. Verdugo and I. A. Belmonte, "Using Digital Stories to Improve Listening Comprehension with Spanish Young Learners of English," Language Learning \& Technology, vol. 11, pp. 87-101, 2007.

[5] R. Garris, R. Ahlers, and J. E. Driskell, "Games, Motivation, and Learning: A Research and Practice Model," Simulation \& Gaming, vol. 33, pp. 441-467, 2002.

[6] J. Thompson, B. Berbank-Green, and N. Cusworth, The computer game design course : principles, practices and techniques for the aspiring game designer. London: Thames \& Hudson, 2007.

[7] L. Gilbert and V. Gale, Principle of E-Learning Systems Engineering. Oxford: Chandos Publishing, 2008.

[8] M. Prensky, Digital Game-Based Learning. New York: McGraw-Hill, 2001.

[9] J. P. Gee, What Video Games Have to Teach Us About Learning and Literacy. New York: Palgrave Macmillan, 2007. 